\title{
External Validation and Sub-cohort Analysis of Stochastic Forecasting Models in NICU Cohorts
}

\author{
Richard P Floyd*, Jennifer L. Dickson*, Aaron J. Le Compte*, J. Geoffrey Chase*, Adrienne Lynn**, \\ Geoffrey M. Shaw*** \\ * Department of Mechanical Engineering, University of Canterbury, Christchurch, New Zealand \\ ** Neonatal Department, Christchurch Women's Hospital, Christchurch, New Zealand \\ *** Department of Intensive Care, Christchurch Hospital, Christchurch, New Zealand
}

\begin{abstract}
Hyperglycaemia is a prevalent complication in the neonatal intensive care unit (NICU) and is associated with worsened outcomes. It occurs as a result of prematurity, under developed endogenous glucose regulatory systems and clinical stress. The stochastic targeting (STAR) framework provides patient-specific, model-based glycaemic control with a clinically proven level of confidence on the outcome of treatment interventions, thus directly managing the risk of hypo- and hyper- glycaemia. However, the stochastic models that are over conservative can limit control performance. Clinical data from 61 episodes (25 retrospective and 36 from a prospective BG control study), of insulin therapy in very-low birth weight (VLBW) and extremely-low birth weight (ELBW) neonates are used to create a new stochastic model of model-based insulin sensitivity $\left(\mathrm{S}_{\mathrm{I}}\right)$. Sub-cohort models based on gestational age (GA) and birth weight (BW) are also created. Performance is assessed by the percentage of patients who have $90 \%$ of actual intra-patient variability in $S_{I}$ captured by the $90 \%$ confidence bands of the cohort based (inter-patient) stochastic variability model created. This assessment measures per-patient accuracy for any given cohort model. Per-patient coverage trends were very similar between prospective and retrospective cohorts, providing a measure of external validation of cohort similarity. Per patient coverage was improved though the use of BW and GA dependent stochastic models, which ensures that the stochastic models more accurately capture both inter- and intra- patient variability. Stochastic forecasting is limited by significant interpatient variability, which implies that more patient specific methods will be required to improve forecasting and glycaemic control.
\end{abstract}

Keywords: Insulin sensitivity, control algorithms, physiological models, simulation, intensive care

\subsection{INTRODUCTION}

Premature infants are a large proportion of neonatal intensive care unit (NICU) populations. Severity of prematurity is commonly quantified by gestational age (GA) and birth weight (BW). Birth weight classifies infants into low birth weight (LBW $<2,500 \mathrm{~g}$ ), very low birth weight (VLBW < $1,500 \mathrm{~g})$ and extremely low birth weight (ELBW $<1,000 \mathrm{~g})$. Similarly GA classifies prematurity as preterm ( $<36$ weeks), very preterm ( $<31$ weeks) and extremely preterm $(<27$ weeks). Each classification carries increased risk of long term complications, impaired development, and mortality with decreasing BW and GA.

Persistent hyperglycaemia is reported in 57\% of ELBW infants (Hays et al. 2006) and 32-86\% of VLBW infants (Beardsall et al. 2010; Cowett et al. 2004). Hyperglycaemia has been linked to worsened outcome, but no study has conclusively determined if hyperglycaemia itself is harmful, or simply represents of severity of condition. The associated negative outcomes include sepsis, increased ventilator dependence, retinopathy of prematurity, increase hospital length of stay, and mortality (Alaedeen et al. 2006; Heimann et al. 2007)
Loss of glucose regulation is a possible cause of hyperglycaemia, as preterm neonates are in a transition from complete dependence on the mother to physiological independence. Hence, metabolic regulation systems are still under development attenuating natural glucose regulation capability. Glucose regulation can be further impaired by clinical stress, which can increase hepatic gluconeogenesis and decrease insulin sensitivity (McCowen et al. 2001).

Hyperglycaemia is typically regarded as blood glucose (BG) greater than $10 \mathrm{mmol} / \mathrm{L}$, but there is no standard definition, nor an accepted threshold for intervention (Alsweiler et al. 2007). The approach to managing hyperglycaemia is different for each NICU, but effective treatment remains elusive. This lack of treatment structure stems in part from the lack of reliable evidence in favour of glycaemic control for preterm neonates (Bottino et al. 2011)

Current treatments include glucose restriction, and insulin. However, glucose restriction (Hemachandra et al. 1999) deprives the neonate of energy vital for growth and development (Cowett et al. 2004), and is therefore not ideal. The American Academy of Pediatrics has supported the use of insulin since 1985 (American Academy of Pediatrics Committee on Nutrition 1985) and several trials have been completed. In particular, using insulin infusions to treat 


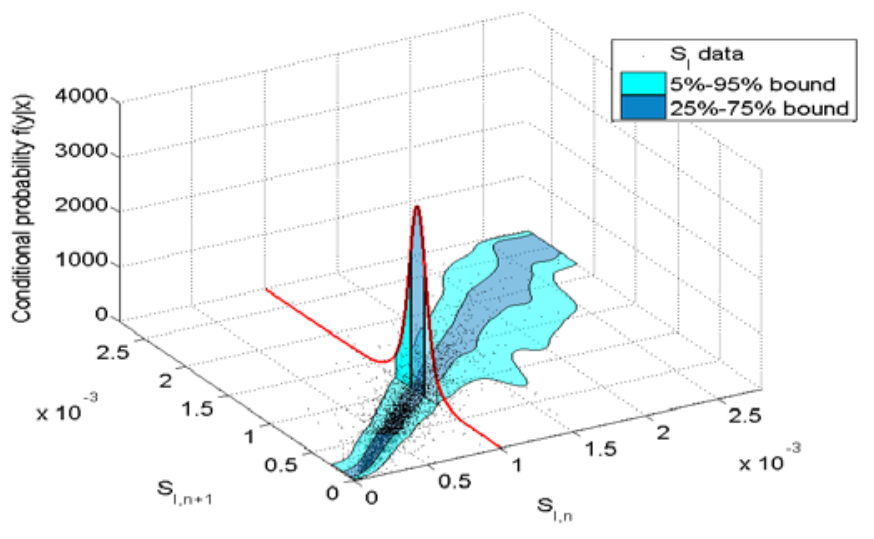

Figure 1: Hourly insulin sensitivity variation data with probability bounds and example curve showing probability bounds.

hyperglycaemia and/or promote growth has shown positive outcomes including reduced proteolysis, improved glucose tolerance, increased IGF-I levels, and improved caloric intake and weight gain (Agus et al. 2004; Beardsall et al. 2007a; Beardsall et al. 2008).

However, many insulin trials were unsuccessful in safely providing glycaemic control due to increased hypoglycaemia (Beardsall et al. 2008; Meetze et al. 1998). The NIRTURE trial was stopped early, in part due to increased hypoglycaemia (Beardsall et al. 2008). All reported insulin therapy trials used protocols that fixed insulin dosing based on weight or other factors (Beardsall et al. 2007b) or depended on clinical judgement to determine insulin infusion rates. Thus, these protocols failed to account for the large variability observed in the insulin sensitivity of neonates (Le Compte et al. 2010). Increased variability with fixed or relatively fixed insulin dosing protocols results in poor control, excessive glycaemic variability and hypoglycaemia (Chase et al. 2011).

This variability is clearly evident in the hour-hour variation in model-based insulin sensitivity $\left(\mathrm{S}_{\mathrm{I}}\right)$ obtained from an analysis of clinical data for preterm VLBW and ELBW neonates (Le Compte et al. 2010), and shown in Figure 1. It shows model-based $S_{\text {I }}$ from a clinically validated model of neonate metabolism (Le Compte et al. 2009) and its variation from one hour $\left(S_{\text {In }}\right)$ to the next $\left(S_{I n+1}\right)$ over a cohort. The potential variation is quite large. Over 3-4 hour measurement and intervention intervals typical in glycaemic control studies these variations, given an exogenous insulin dose, can result in significant unanticipated changes in BG levels. Only the Stochastic TARgeted, model-based controller (Le Compte et al. 2009) directly accounts for this variation in dosing and has been the clinical standard of care in Christchurch Women's Hospital since 2009.

However, this stochastic model can be too conservative for some neonates, with wide stochastic forecasting bands that are not representative of all neonates resulting in low doses of insulin and persistently high BG. To enable better and equally safe control for all patients, the stochastic models need to be improved. One avenue is to create stochastic models for the variation of $S_{I}$ over specific sub-cohorts by GA and BW, which are variables readily available at bedside. The goal is to create models that not only account for inter-patient variability over cohorts, but also capture intra-patient variability (per-patient) more accurately.

\section{METHODS}

\subsection{System model}

The clinically validated (Le Compte et al. 2009) NICING model variables are defined in Table 1 , and is defined:

$$
\begin{gathered}
\dot{G}=-p_{G} G(t)-S_{I} G(t) \frac{Q(t)}{1+\alpha_{G} Q(t)} \\
+\frac{P(t)+E G P * m_{\text {body }}-C N S * m_{\text {brain }}}{V_{g_{s} f r a c}(t) * m_{\text {body }}} \\
\dot{I}=-\frac{n_{L} I(t)}{1+\alpha_{I} I(t)}-n_{K} I(t)-n_{I}(I(t)-Q(t)) \\
+\frac{u_{e x}(t)}{V_{I_{\text {frac }}} * m_{\text {body }}}+\left(1-x_{L}\right) \frac{u_{e n}(G)}{V_{l, f r a c} * m_{\text {body }}} \\
\dot{Q}=n_{I}(I(t)-Q(t))-n_{C} \frac{Q(t)}{1+\alpha_{G} Q(t)} \\
\dot{P}_{1}=-d_{1} P_{1}+P(t) \\
\dot{P}_{2}=-\min _{2}\left(d_{2} P_{2}, P_{\max }\right)+d_{1} P_{1} \\
P(t)=\min _{2}\left(d_{2} P_{2}, P_{\max }\right)+P N(t) \\
u_{e n}=\mathrm{I}_{\mathrm{B}} e^{\frac{-k_{l} u_{e x}}{V_{I}}}
\end{gathered}
$$

\subsection{Clinical Patients}

$\mathrm{S}_{\text {I }}$ profile was fitted from clinical data using Equations (1)(7). This clinically validated method (Chase et al. 2010) allows the performance and stochastic forecasting of STAR to be optimised before clinical trials.

The patient cohort consists of data from 21 retrospective patients (with 25 patient episodes), and 8 short term and 22 long term patients from a prospective BG control study using STAR. The 8 short term patients received insulin therapy for 24 hours in a validation trial of the existing model and controller (Le Compte et al. 2009). Long term patients were treated using STAR as a standard of care at Christchurch Women's Hospital. There are 61 clinical patient datasets, as there are 28 treatment episodes for the 22 long term patients.

\subsection{Improving Stochastic Forecasting with Increased Cohort}

The current stochastic model used in the STAR controller was designed using a retrospective cohort of 25 patients (Le Compte et al. 2010). Hence, the relevance of its performance in virtual trials may be limited. A stochastic matrix created using the larger 61 virtual patient cohort is compared to the current stochastic matrix.

Performance for 3-hour forecast intervals is compared. A perfect model would capture $90 \%$ of each individual patient's variations in the $5-95^{\text {th }}$ percentile interval, but this may vary for individual patients. Performance is assessed by the percentage of patients whose individual stochastic performance comes close to this ideal, for a more accurate and general the stochastic model. 


\subsection{Improving Stochastic Forecasting in Sub-Cohorts}

Two variables easily identified at the bedside are birth weight (BW) and gestational age (GA). Stochastic model matrices are created for each variable by tertiles. A KolmogorovSmirnov (KS) test was used over a full range of possible BW and GA groupings to identify groups with the greatest differences in relative change in insulin sensitivity to create additional stochastic models to differentiate behaviours. Performance is assessed using per-patient coverage.

\subsection{RESULTS}

\subsection{Stochastic Forecasting with Increased Cohort}

Figure 2 shows the per-patient coverage of the $5^{\text {th }}$ to $95^{\text {th }}$ percentile of forecasted change in $S_{I}$ for the current $(N=25)$, short/ long term trial based $(\mathrm{N}=36)$, and new $(\mathrm{N}=61)$ wholecohort stochastic models. There is no significant difference between the per-patient coverage of the different stochastic matrices. All stochastic matrices have a minimum coverage over $70 \%$ and tight distributions around $90 \%$. This result provides a measure of external validation in that the retrospective $(\mathrm{N}=25)$ cohort showed similar performance to the prospective $(\mathrm{N}=36)$ cohort. The same results can be seen for 2 and 4 hour measurement intervals (not shown). However, small improvements can be seen in the coverage distribution for the new whole-cohort stochastic matrix ( $\mathrm{N}=61$ ). It is important to note that Figure 2 is the per-patient coverage, and not all patients have equal number of measurements and thus, do not have the same weighting on stochastic model forecast limits. In addition, manipulation of stochastic matrices to bring the overall whole-cohort percentage coverage closer to the target $90 \%$ tends to adjust the percentiles to capture a single data point, thus making the matrix more cohort-specific and adding no extra value for use outside of the existing cohort.

\subsection{Gestational Age and Birth Weight Sub-Cohort}

The cumulative distribution functions (CDFs) of $S_{I}$ for tertiles of BW and GA are shown in Figures 3 and 4 . The lower tertile has significantly lower $\mathrm{S}_{\mathrm{I}}$ than the other groups for both GA and BW ( $p<0.05$, KS-test). In both cases, the relative changes in $S_{I}$ (lower plot) are not significantly different. Thus, these tertiles are different in absolute $S_{I}$, but not in variability.

Table 3 shows the results for the tertiles in Figures 3-4, as well as other statistically significant cut-off values found ( $\mathrm{p}<$ 0.05 ) for $S_{I}$ over BW and GA sub-cohorts. Figure 5 shows the resulting per-patient coverage for each of the sub-cohort

Table 2: Clinical patient summary statistics.

\begin{tabular}{|c|c|c|c|c|c|c|c|c|c|c|}
\hline \multirow[t]{2}{*}{ taver } & \multicolumn{4}{|c|}{ Short-term $(\mathrm{N}=8)$} & \multicolumn{3}{|c|}{ Long-term $(\mathrm{N}=28)$} & \multicolumn{3}{|c|}{ Retrospective $(\mathrm{N}=25)$} \\
\hline & Median & [IQR] & & & Median & [IQR] & & Median & [IQR] & \\
\hline Gestational age at birth (weeks) & 25.6 & {$[24.9$} & - & $26.4]$ & {$[25.4$} & {$[25.0$} & 26.8] & 26.6 & {$[25.4$} & 27.7 \\
\hline Weight at birth (grams) & 745 & {$[681$} & - & 814] & 760 & {$[601$} & 925] & 845 & {$[800$} & - 904] \\
\hline Age at start of trial (days) & 6.6 & {$[3.6$} & - & 7.7] & 3.6 & {$[1.5$} & - 6.4] & $\mathrm{n} / \mathrm{a}$ & & \\
\hline
\end{tabular}

Table 1: Glucose-insulin metabolic model variable definition

\begin{tabular}{|c|c|c|c|}
\hline Variable & \multicolumn{2}{|c|}{ Description } & Values \\
\hline$G$ & \multicolumn{2}{|c|}{ Blood glucose level } & $(\mathrm{mmol} / \mathrm{L})$ \\
\hline$I$ & \multicolumn{2}{|c|}{ Plasma insulin concentration } & $(\mathrm{mU} / \mathrm{L})$ \\
\hline$Q$ & \multicolumn{2}{|c|}{$\begin{array}{l}\text { Interstitial insulin } \\
\text { concentration }\end{array}$} & $(\mathrm{mU} / \mathrm{L})$ \\
\hline$p_{G}$ & \multicolumn{2}{|c|}{$\begin{array}{l}\text { Endogenous glucose } \\
\text { clearance }\end{array}$} & $0.0030\left(\mathrm{~min}^{-1}\right)$ \\
\hline$\alpha_{G}$ & \multicolumn{2}{|c|}{$\begin{array}{l}\text { Saturation parameter for } \\
\text { insulin mediated glucose } \\
\text { removal }\end{array}$} & $0(\mathrm{~L} / \mathrm{mU})$ \\
\hline$\alpha_{I}$ & \multicolumn{2}{|c|}{$\begin{array}{l}\text { Saturation parameter for } \\
\text { plasma insulin clearance }\end{array}$} & $0.0017(\mathrm{~L} / \mathrm{mU})$ \\
\hline$S_{I}$ & \multicolumn{2}{|c|}{ Insulin sensitivity } & (L/mU/min) \\
\hline EGP & \multicolumn{2}{|c|}{$\begin{array}{l}\text { Endogenous glucose } \\
\text { production }\end{array}$} & $\begin{array}{c}0.0284 \\
(\mathrm{mmol} / \mathrm{min})\end{array}$ \\
\hline CNS & \multicolumn{2}{|c|}{$\begin{array}{l}\text { Central nervous system } \\
\text { glucose uptake }\end{array}$} & $\begin{array}{c}0.088 \\
(\mathrm{mmol} / \mathrm{min})\end{array}$ \\
\hline$P(t)$ & \multicolumn{2}{|c|}{$\begin{array}{l}\text { Glucose appearance in plasma } \\
\text { from dextrose intake }\end{array}$} & (mmol/min) \\
\hline$P N$ & \multicolumn{2}{|c|}{ Parenteral Nutrition } & (mmol/min) \\
\hline $\boldsymbol{P}_{\max }$ & \multicolumn{2}{|c|}{$\begin{array}{l}\text { Maximal glucose flux from } \\
\text { gut to plasma }\end{array}$} & $\begin{array}{c}6.11 \\
(\mathrm{mmol} / \mathrm{min})\end{array}$ \\
\hline$P 1$ & \multicolumn{2}{|c|}{ Glucose level in stomach } & (mmol) \\
\hline$P 2$ & \multicolumn{2}{|c|}{ Glucose level in gut } & (mmol) \\
\hline$V_{G}$ & \multicolumn{2}{|c|}{$\begin{array}{l}\text { Plasma glucose distribution } \\
\text { volume }\end{array}$} & $0.5961(\mathrm{~L})$ \\
\hline$k_{I}$ & \multicolumn{2}{|c|}{$\begin{array}{l}\text { Interstitial insulin transport } \\
\text { rate }\end{array}$} & $0.1\left(\min ^{-1}\right)$ \\
\hline$I_{B}$ & \multicolumn{2}{|c|}{$\begin{array}{l}\text { Endogenous insulin } \\
\text { production }\end{array}$} & $15[\mathrm{mU} / \mathrm{L} / \mathrm{min}]$ \\
\hline$n_{I}$ & \multicolumn{2}{|c|}{$\begin{array}{l}\text { Rate of transport between } \\
\text { plasma and interstitial insulin } \\
\text { compartments }\end{array}$} & $0.003\left(\mathrm{~min}^{-1}\right)$ \\
\hline$n_{K}$ & \multicolumn{2}{|c|}{ Renal insulin clearance } & $0.150\left(\min ^{-1}\right)$ \\
\hline$n_{L}$ & \multicolumn{2}{|c|}{ Hepatic insulin clearance } & $1\left(\min ^{-1}\right)$ \\
\hline$n_{C}$ & \multicolumn{2}{|c|}{ Interstitial insulin degradation } & $0.003\left(\mathrm{~min}^{-1}\right)$ \\
\hline$x_{L}$ & \multicolumn{2}{|c|}{$\begin{array}{l}\text { First-pass hepatic insulin } \\
\text { clearance }\end{array}$} & 0.67 \\
\hline$u_{e x}(t)$ & \multicolumn{2}{|c|}{ Exogenous insulin } & $(\mathrm{mU} / \mathrm{min})$ \\
\hline$u_{e n}(t)$ & \multicolumn{2}{|c|}{$\begin{array}{l}\text { Endogenous insulin } \\
\text { production }\end{array}$} & (mU/min) \\
\hline$V_{I}$ & \multicolumn{2}{|c|}{$\begin{array}{l}\text { Plasma insulin distribution } \\
\text { volume }\end{array}$} & $0.0450(\mathrm{~L})$ \\
\hline$d_{1}$ & \multicolumn{2}{|c|}{$\begin{array}{l}\text { Glucose absorption rate from } \\
\text { stomach }\end{array}$} & $0.0347\left(\mathrm{~min}^{-1}\right)$ \\
\hline$d_{2}$ & \multicolumn{2}{|c|}{$\begin{array}{l}\text { Glucose absorption rate from } \\
\text { gut }\end{array}$} & $0.0069\left(\mathrm{~min}^{-1}\right)$ \\
\hline$D(t)$ & \multicolumn{2}{|l|}{ Dextrose intake } & (mmol/min) \\
\hline$m_{b o d y}$ & Body mass & & (kg) \\
\hline$m_{\text {brain }}$ & Brain mass (14 & $\left.m_{\text {body }}\right)$ & (kg) \\
\hline Long-ter & $(\mathrm{N}=28)$ & Retrospectiv & ve $(\mathrm{N}=25)$ \\
\hline Median & [IQR] & \begin{tabular}{|l|l} 
Median & [IC \\
\end{tabular} & $\mathrm{QR}]$ \\
\hline$[25.4$ & $\begin{array}{ll}- & 26.8]\end{array}$ & 26.6 & 27.7] \\
\hline 760 & - 925] & 845 & 904] \\
\hline 3.6 & $\begin{array}{ll}-\quad 6.4] \\
\end{array}$ & $\mathrm{n} / \mathrm{a}$ & \\
\hline
\end{tabular}




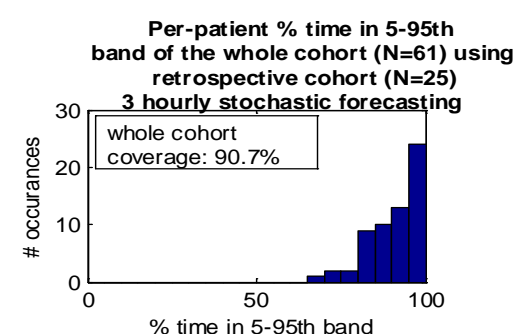

Per-patient percentage time in 25-75th band of the whole cohort $(\mathrm{N}=61)$ using retrospective cohort $(\mathrm{N}=25)$

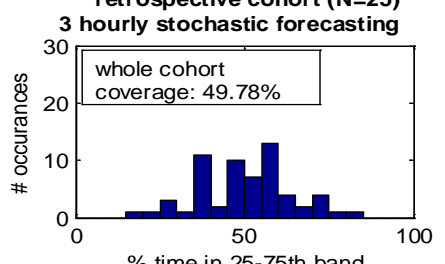

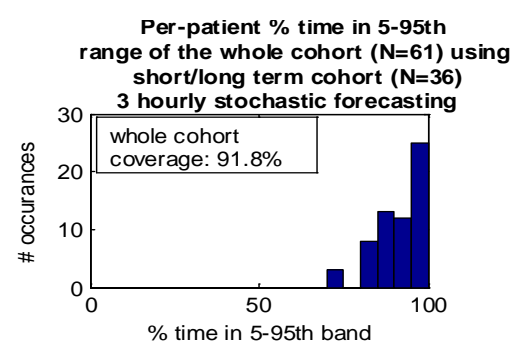

Per-patient percentage time in 25-75th range of the whole cohort $(\mathrm{N}=61)$ using short/long term cohort $(\mathrm{N}=36)$

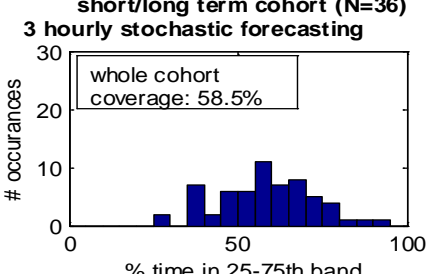

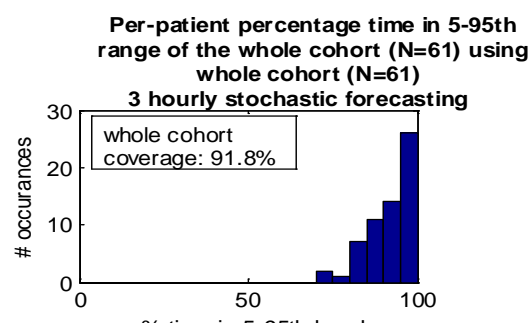

$\%$ time in 5-95th band

Per-patient percentage time in 25-75th range of the whole cohort $(\mathrm{N}=61)$ using whole cohort $(\mathrm{N}=61)$

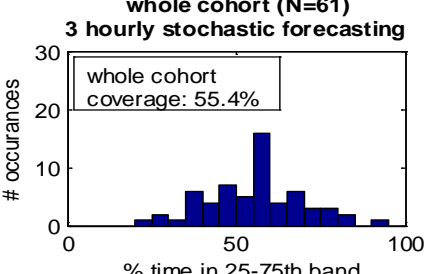

Figure 2: Per-patient coverage between the forecasted $5^{\text {th }}$ and $95^{\text {th }}$ percentile change in insulin sensitivity using the current stochastic matrix compared with new stochastic matrix. ( $\mathrm{N}=$ number of patients used to create stochastic matrix).

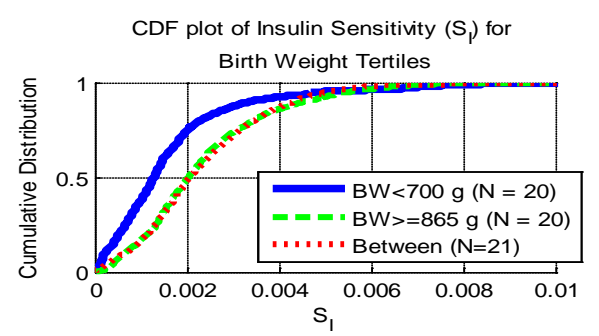

CDF plot of Relative Change in Insulin Sensitivity $\left(S_{p}\right)$ for

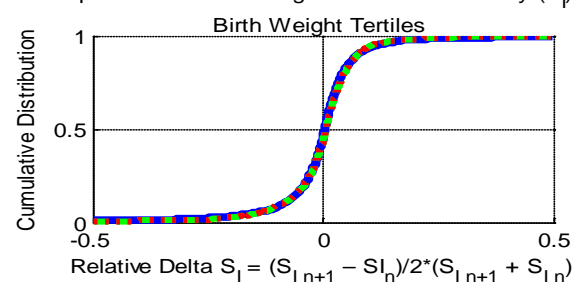

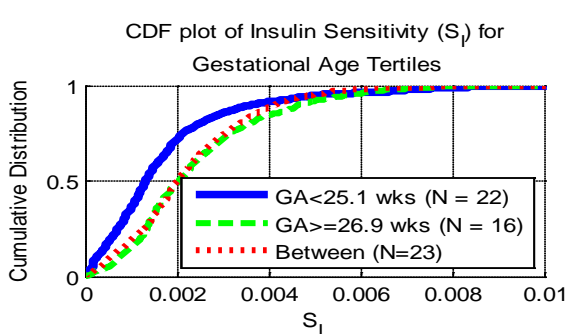

CDF plot of Relative Change in Insulin Sensitivity (S)

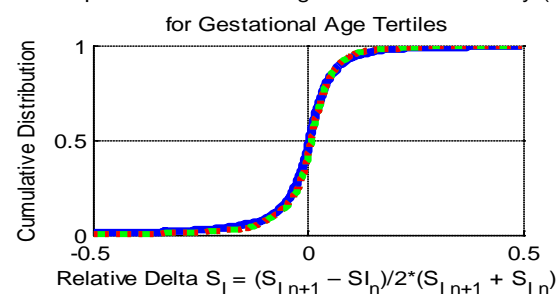

Figure 3: Correlation of insulin sensitivity and change in insulin sensitivity with birth weight.
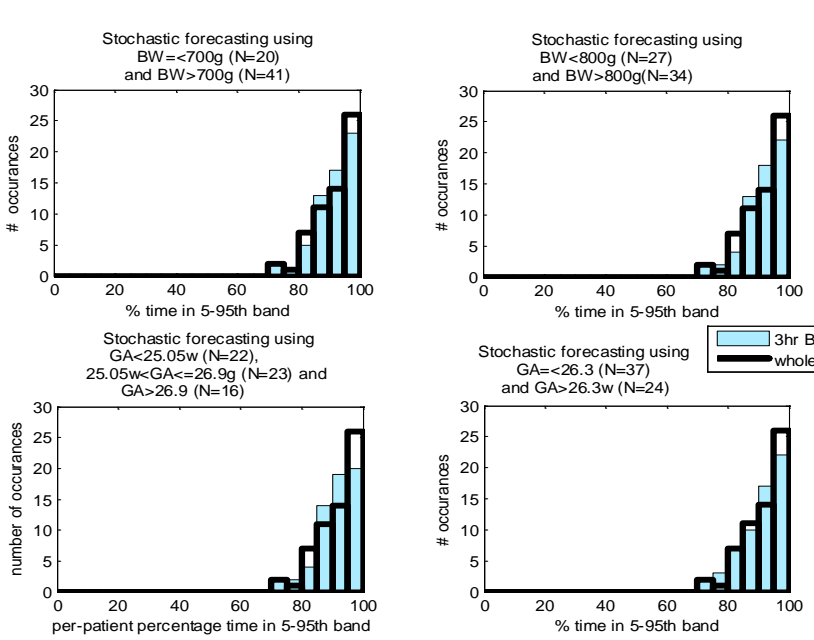
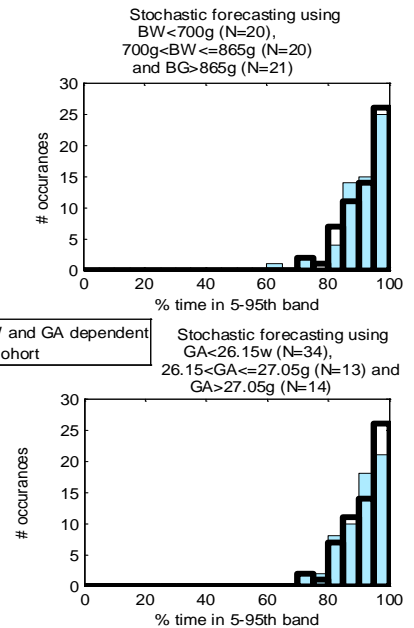

Figure 4: Correlation of insulin sensitivity and change in insulin sensitivity with gestational age.

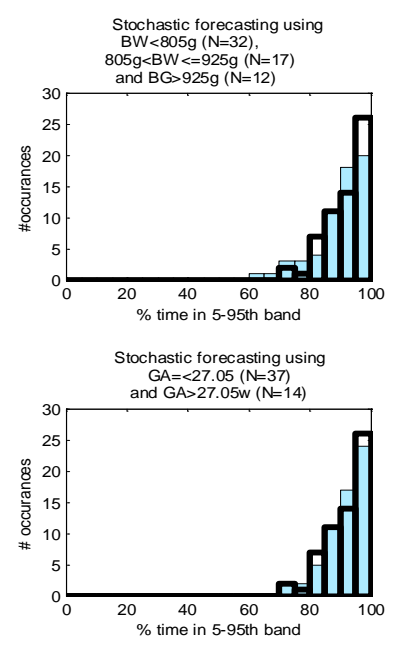

Figure 5: Comparison of per-patient coverage for BW and GA dependent point to point 4 hourly stochastic forecasting. 
Table 3: Effect of weight and gestational age on insulin sensitivity statistics.

\begin{tabular}{|c|c|c|c|c|}
\hline Data Set & $\begin{array}{cl}\mathrm{S}_{\mathrm{I}} & -\mathrm{Median}[\mathrm{IQR}] \\
& (\mathrm{L} / \mathrm{mU} / \mathrm{min})\end{array}$ & $\begin{array}{c}\text { Relative delta } S_{I}-\text { Median (P) } \\
{[I Q R]}\end{array}$ & \# hours & \#Patients \\
\hline Whole Cohort & $0.0017[0.0010-0.0027]$ & $0.004204[-0.0303-0.0351]$ & 6968 & 61 \\
\hline BW $<700 \mathrm{~g}$ & $0.0013[0.0007-0.0020]$ & $0.004116[-0.0299-0.0339]$ & 3032 & 20 \\
\hline BW $>865 g$ & $0.0020[0.0013-0.0031]$ & $0.006074[-0.0289-0.0376]$ & 1426 & 20 \\
\hline $700 \mathrm{~g}<\mathrm{BW}<865 \mathrm{~g}$ & $0.0021[0.0013-0.0032]$ & $0.003114[-0.0312-0.0360]$ & 2510 & 21 \\
\hline BW $<805 g$ & $0.0015[0.0008-0.0025]$ & $0.003640[-0.0310-0.0344]$ & 4566 & 32 \\
\hline BW $>925 g$ & $0.0024[0.0015-0.0037]$ & $0.008583[-0.0194-0.0353]$ & 748 & 12 \\
\hline $805 g<$ BW $<925 g$ & $0.0019[0.0013-0.0030]$ & $0.003678[-0.0312-0.0385]$ & 1654 & 17 \\
\hline BW $<700 \mathrm{~g}$ & $0.0013[0.0007-0.0020]$ & $0.004116[-0.0299-0.0339]$ & 3032 & 20 \\
\hline $\mathrm{BW}>700 \mathrm{~g}$ & $0.0021[0.0013-0.0032]$ & $0.004254[-0.0305-0.0369]$ & 3907 & 40 \\
\hline $\mathrm{BW}<\mathbf{8 0 0 \mathrm { g }}$ & $0.0014[0.0007-0.0021]$ & $0.003866[-0.0289-0.0334]$ & 3519 & 27 \\
\hline $\mathrm{BW}>800 \mathrm{~g}$ & $0.0021[0.0013-0.0033]$ & $0.004446[-0.0315-0.0382]$ & 3449 & 34 \\
\hline GA $<25.1 w k s$ & $0.0013[0.0007-0.0021]$ & $0.004001[-0.0314-0.0343]$ & 3196 & 22 \\
\hline GA $>26.9 w k s$ & $0.0020[0.0013-0.0032]$ & $0.008319[-0.0215-0.0370]$ & 1200 & 16 \\
\hline $25.1<$ GA $<26.9$ wks & $0.0020[0.0013-0.0031]$ & $0.002614[-0.0316-0.0364]$ & 2572 & 23 \\
\hline GA $<26.15 w k s$ & $0.0015[0.0008-0.0026]$ & $0.003139[-0.0316-0.0340]$ & 4561 & 34 \\
\hline GA $>27.05 w k s$ & $0.0021[0.0014-0.0033]$ & $0.008422[-0.0205-0.0374]$ & 1141 & 14 \\
\hline 26.15wks $<$ GA $<27.05$ wks & $0.0019[0.0013-0.0027]$ & $0.004314[-0.0315-0.0389]$ & 1266 & 13 \\
\hline GA $<26.3$ wks & $0.0015[0.0008-0.0026]$ & $0.003138[-0.0310-0.0340]$ & 4842 & 37 \\
\hline GA $>26.3$ wks & $0.0020[0.0014-0.0030]$ & $0.007230[-0.0287-0.0385]$ & 2126 & 24 \\
\hline GA $<27.05$ wks & $0.0016[0.0009-0.0026]$ & $0.003364[-0.0316-0.0349]$ & 5827 & 47 \\
\hline GA $>27.05$ wks & $0.0021[0.0014-0.0033]$ & $0.008422[-0.0205-0.0374]$ & 1141 & 14 \\
\hline
\end{tabular}

groups in Table 3. There is noticeable improvement from the whole cohort $(\mathrm{N}=61)$ result shown for comparison. Thus, the BW and GA dependent models add greater resolution and per-patient accuracy.

\subsection{DISCUSSION}

Comparison of per-patient percentile band coverage for different cohort based stochastic matrices has shown that the cohorts are essentially similar in behaviour. The addition of 36 patient episodes ( $\mathrm{N}=25$ to $\mathrm{N}=61$ ) has improved per-patient stochastic model coverage slightly. This similarity in coverage with the use of different cohort stochastic forecasting verifies that the original data set is as representative of the NICU population as previously thought, where initial work with stochastic matrices in adult ICU patients indicated $\mathrm{N}=25$ would be suitable (Lin et al. 2006).

The high proportion of coverage above $90 \%$, and in particular above $95 \%$ in the $5-95^{\text {th }}$ band suggests that this band width is determined by the behaviour of a few patients. Ideally, for patient specificity, the majority of per-patient coverage would be around the target $90 \%$. The patient coverage of the $25-75^{\text {th }}$ percentiles is much wider, indicating significant inter-patient variability within these bounds. In particular, the short and long term cohorts have higher average coverage in the $25^{\text {th }}$ $75^{\text {th }}$ band suggesting that differences between cohorts arise within the extremes of behaviour. Overall it seems that interpatient variation is more significant than intra-patient variation as a limiting factor in this stochastic forecasting model and patients are essentially different in behaviour.
BW and GA dependent stochastic models can be used to further improve per-patient coverage, as seen in Figure 5. The proportion of coverage around the $90 \%$ target for the $5-95^{\text {th }}$ percentiles is much greater, indicating BW and GA can be used to introduce greater patient specificity in stochastic forecasting. Due to the relatively small number of patients used, the ideal combinations of BW and GA found may not fully represent all NICU populations or be perfect divisions for other NICU cohorts. Equally, there may be differences between NICUs due to differences in cohort or case mix. However, the results clearly illustrate potential to improve patient-specific forecasting and glycaemic control based on easily measured variables. Further investigations using larger independent cohorts should be completed to validate these initial insights, and create more generalisable results. However, these results provide a template for further analysis.

\subsection{CONCLUSIONS}

Stochastic model based forecasting based on a larger patient database provides a more accurate representation of the NICU population, but is limited by inter-patient variability. Birth weight and gestational age dependent stochastic forecasting can be used to further increase per-patient accuracy and coverage. Increased per-patient coverage improves patient-specific accuracy and thus has potential to improve the performance and safety from hypoglycaemia of model based glycaemic control for preterm infants in the NICU. Significant inter-patient variability as a dominant 
factor implies more patient-specific methods will be required to improve further.

\subsection{REFERENCES}

Agus, MS, Javid, PJ, Ryan, DP \& Jaksic, T 2004, 'Intravenous insulin decreases protein breakdown in infants on extracorporeal membrane oxygenation', Journal of pediatric surgery, vol. 39, no. 6, pp. 839-44.

Alaedeen, DI, Walsh, MC \& Chwals, WJ 2006, 'Total parenteral nutrition-associated hyperglycemia correlates with prolonged mechanical ventilation and hospital stay in septic infants', J Pediatr Surg, vol. 41, no. 1, pp. 239-44.

Alsweiler, JM, Kuschel, CA \& Bloomfield, FH 2007, 'Survey of the management of neonatal hyperglycaemia in Australasia', Journal of Paediatrics and Child Health, vol. 43, no. 9, pp. 632-5.

American Academy of Pediatrics Committee on Nutrition 1985, 'Nutritional needs for low-birth-weight infants.', Pediatrics, vol. 75, pp. 976-86.

Beardsall, K, Ogilvy-Stuart, AL, Frystyk, J, Chen, JW, Thompson, M, Ahluwalia, J, Ong, KK \& Dunger, DB 2007a, 'Early elective insulin therapy can reduce hyperglycemia and increase insulin-like growth factor-I levels in very low birth weight infants', The Journal of pediatrics, vol. 151, no. 6, pp. 611-7.

Beardsall, K, Vanhaesebrouck, S, Ogilvy-Stuart, AL, Ahluwalia, JS, Vanhole, C, Palmer, C, Midgley, P, Thompson, M, Cornette, L, Weissenbruch, M, Thio, M, de Zegher, F \& Dunger, D 2007b, 'A randomised controlled trial of early insulin therapy in very low birth weight infants, "NIRTURE" (neonatal insulin replacement therapy in Europe)', BMC pediatrics, vol. 7, p. 29.

Beardsall, K, Vanhaesebrouck, S, Ogilvy-Stuart, AL, Vanhole, C, Palmer, CR, Ong, K, vanWeissenbruch, M, Midgley, P, Thompson, M, Thio, M, Cornette, L, Ossuetta, I, Iglesias, I, Theyskens, C, de Jong, M, Gill, B, Ahluwalia, JS, de Zegher, F \& Dunger, DB 2010, 'Prevalence and determinants of hyperglycemia in very low birth weight infants: cohort analyses of the NIRTURE study', J Pediatr, vol. 157, no. 5, pp. 715-9 e1-3.

Beardsall, K, Vanhaesebrouck, S, Ogilvy-Stuart, AL, Vanhole, C, Palmer, CR, van Weissenbruch, M, Midgley, P, Thompson, M, Thio, M, Cornette, L, Ossuetta, I, Iglesias, I, Theyskens, C, de Jong, M, Ahluwalia, JS, de Zegher, F \& Dunger, DB 2008, 'Early Insulin Therapy in Very-Low-Birth-Weight Infants', $N$ Engl J Med, vol. 359, no. 18, pp. 1873-84.

Bottino, M, Cowett, RM \& Sinclair, JC 2011, 'Interventions for treatment of neonatal hyperglycemia in very low birth weight infants', Cochrane Database Syst Rev, no. 10.

Chase, JG, Le Compte, AJ, Suhaimi, F, Shaw, GM, Lynn, A, Lin, J, Pretty, CG, Razak, N, Parente, JD, Hann, CE, Preiser, J-C \& Desaive, T 2011, 'Tight glycemic control in critical care - The leading role of insulin sensitivity and patient variability: A review and model-based analysis', Computer Methods and Programs in Biomedicine, vol. 102, no. 2, pp. 156-71.

Chase, JG, Suhaimi, F, Penning, S, Preiser, JC, Le Compte, AJ, Lin, J, Pretty, CG, Shaw, GM, Moorhead, KT \& Desaive, T 2010, 'Validation of a model-based virtual trials method for tight glycemic control in intensive care', Biomed Eng Online, vol. 9, p. 84.

Cowett, RM \& Farrag, HM 2004, 'Selected principles of perinatal-neonatal glucose metabolism', Semin Neonatol, vol. 9, no. 1, pp. 37-47.

Hays, SP, Smith, B \& Sunehag, AL 2006, 'Hyperglycemia Is a Risk Factor for Early Death and Morbidity in Extremely Low Birth-Weight Infants', Pediatrics, vol. 118, no. 5, pp. 1811-8.

Heimann, K, Peschgens, T, Kwiecien, R, Stanzel, S, Hoernchen, H \& Merz, U 2007, 'Are recurrent hyperglycemic episodes and median blood glucose level a prognostic factor for increased morbidity and mortality in premature infants $</=1500$ g?', Journal of perinatal medicine, vol. 35, no. 3, pp. 245-8.

Hemachandra, AH \& Cowett, RM 1999, 'Neonatal Hyperglycemia', Peds in Review, vol. 20, no. 7, pp. 16-24.

Le Compte, A, Chase, J, Lynn, A, Hann, C, Shaw, G, Wong, X \& Lin, J 2009, 'Blood Glucose Controller for Neonatal Intensive Care: Virtual trials development and 1st clinical trials', Journal of Diabetes Science and Technology, vol. 3, no. 5, pp. 1066-81.

Le Compte, AJ, Lee, DS, Chase, JG, Lin, J, Lynn, A \& Shaw, GM 2010, 'Blood glucose prediction using stochastic modeling in neonatal intensive care', IEEE Trans Biomed Eng, vol. 57, no. 3, pp. 509-18.

Lin, J, Lee, D, Chase, J, Hann, C, Lotz, T \& Wong, X 2006, 'Stochastic Modelling of Insulin Sensitivity Variability in Critical Care', Biomedical Signal Processing \& Control, vol. 1, pp. 229-42.

McCowen, KC, Malhotra, A \& Bistrian, BR 2001, 'Stressinduced hyperglycemia', Crit Care Clin, vol. 17, no. 1, pp. 107-24.

Meetze, W, Bowsher, R, Compton, J \& Moorehead, H 1998, 'Hyperglycemia in extremely- low-birth-weight infants', Biol Neonate, vol. 74, no. 3, pp. 214-21. 